\title{
Digital Technologies as Tools for Managing the Regional Health System
}

\author{
Petrova T.N.* \\ Voronezh State Medical University, \\ Voronezh, Russia \\ e-mail: Stud.forum@mail.ru
}

Goncharov A.Yu.

Voronezh State Medical University, Voronezh, Russia

e-mail: Alex.g007@mail.ru

Zolotykh T.M.

VOCOD, Deputy Chief Physician

e-mail: Zolotykh@mail.ru

\author{
Deryaeva A.G. \\ Voronezh State Medical University, \\ Voronezh, Russia \\ e-mail: Aleshkastaryi1994@mail.ru
}

Koval N.A.

Voronezh State Medical University,

Voronezh, Russia

e-mail: Nikolai_koval@list.ru

\author{
Burdantseva A.A. \\ Voronezh State University, \\ Voronezh, Russia \\ e-mail: burdantseva@icloud.com
}

\begin{abstract}
Actual issues of digitalization of the health care sphere are stated in the article. The authors analyze the stages of informatization and the appearance of new digital technologies in medicine. Based on economic, static and meaningful research methods, the main advantages and limitations of using digital technologies in healthcare are stated, and the basic concept of creating an information network of a large industrial region is described. Based on foreign experience, the social and economic efficiency of innovative telemedical technologies is justified. The review of the results of the creation of regional fragments of the Single State Information System of Health Care (SSISHC) was carried out. The analysis of the implementation of regional programs for the development of a unified digital circuit and the introduction of innovative technologies in the field of health care was carried out. Authors focus on such practical aspects as electronic document management, remote monitoring of the patient's condition, telecommunication interaction between medical workers and organizations. Special attention is paid to difficulties, problems, and contradictions of the introduction of information technologies in the sphere of public health services. The statistical data on the intermediate results of the regional information system implementation are analyzed, testifying to the correctness of the taken decisions on designing and implementation of the SSISHC. The main measures planned by the regions and criteria of their effectiveness are given. Several problems that have arisen in the process of implementation of projects aimed at informatization and high-tech support of the health care system are highlighted. It is shown that in addition to solving exclusively medical tasks, the application of information technologies in the regional social function contributes to optimizing the management of the health care institution, distance training of medical workers and exchange of experience. The article is of practical importance as it can be used for the preparation of technical tasks for the modernization and maintenance of medical information systems of medical organizations.
\end{abstract}

Keywords - common state information system of health care; information technologies; health care informatization.

\section{INTRODUCTION}

In recent years Russia has undergone a serious modernization and development of health care, an integral part of which is the development of informatization with the creation of a single digital circuit and the introduction of innovative technologies $[11,12]$.

Some states have been actively using innovations in the medical sphere for a long time. These include teleconsultation of patients and staff, remote monitoring and recording of physiological parameters, exchange of patient data between medical organizations, etc. [2, 4, 6, 9]. In Russia, there are also digital platforms for interaction between medical professionals, and these communications have been partially implemented to the doctor-patient. However, this is not enough. The main task of technological transformation is the creation and implementation of the Single State Information System of Health Care (SSISHC). The solution of this task will make it possible to increase the efficiency of management in the sphere of health care, to solve the problems of intensification of the use of health care resources and the quality of medical services $[3,5]$.

Today, the regional level of health care management occupies a special place in the system of organization of medical care for the country's population. The noticeable shift of health care informatization towards the regional level is explained not only by the growing independence of territories and the disappearance of centralized supplies of equipment and programs [7, 10]. Heads of healthcare authorities at different levels are increasingly permeated by the idea that effective management can only be expected if all Russian regions are involved in the informatization process at the 
federal level and all functional and structural subdivisions of the regional level. It is here that the global goals of the state level are transformed into specific tasks of health care bodies and institutions and, ultimately, their success or failure is ensured. It is quite natural that informatization of health care management at the regional level is also central $[10,13,14]$.

\section{METHODS AND MATERIALS}

The object of this research was a regional medical information system developed and adapted to the activities of Voronezh Region health care system. The research was based on structural system analysis, the methodology of conceptual (logical) modeling, the theory of sets and technologies of information systems development.

\section{RESULTS}

Work on the modernization of the Regional Health Information Organization (RHIO) with the creation of federal components of the system has been actively carried out since 2011 to date. In the Voronezh Region, these works have also been carried out purposefully and efficiently for many years now. Measures to develop information technologies are defined by Voronezh Region state program Healthcare Development and the Road Map for the development of SSISHC. Among the most important problems of informatization of the region there is the inclusion of all structural subdivisions of the region into the system of information collection and processing, as well as gradual coverage by informatization of the main functions inherent to the regional public health authority. The solution to these problems, even at present, is still far from being completed and is ambiguous at various stages of development.

At present, the proportion of automated workplaces for medical personnel connected to medical information systems is $92.75 \%$ (85.97\% in 2017).

The percentage of doctors providing medical care in outpatient conditions, the data on the schedule of appointments for which are transmitted to the subsystem of the federal electronic registration system of SSISHC also increased 1.2 times and amounted to $66.81 \%(2017-53.81 \%)$.

The Voronezh region was allocated an inter-budgetary transfer of 29 million rubles. Within the framework of the implementation of the Russian Federation Government Regulation No. 659-r of 12.04.2018, the works on modernization of the Voronezh Region state information system of the regional SSISHC system for the implementation of electronic medical document flow, exchange of medical documents in the form of electronic documents between medical organizations, automated interaction with the federal SSISHC services have been started.

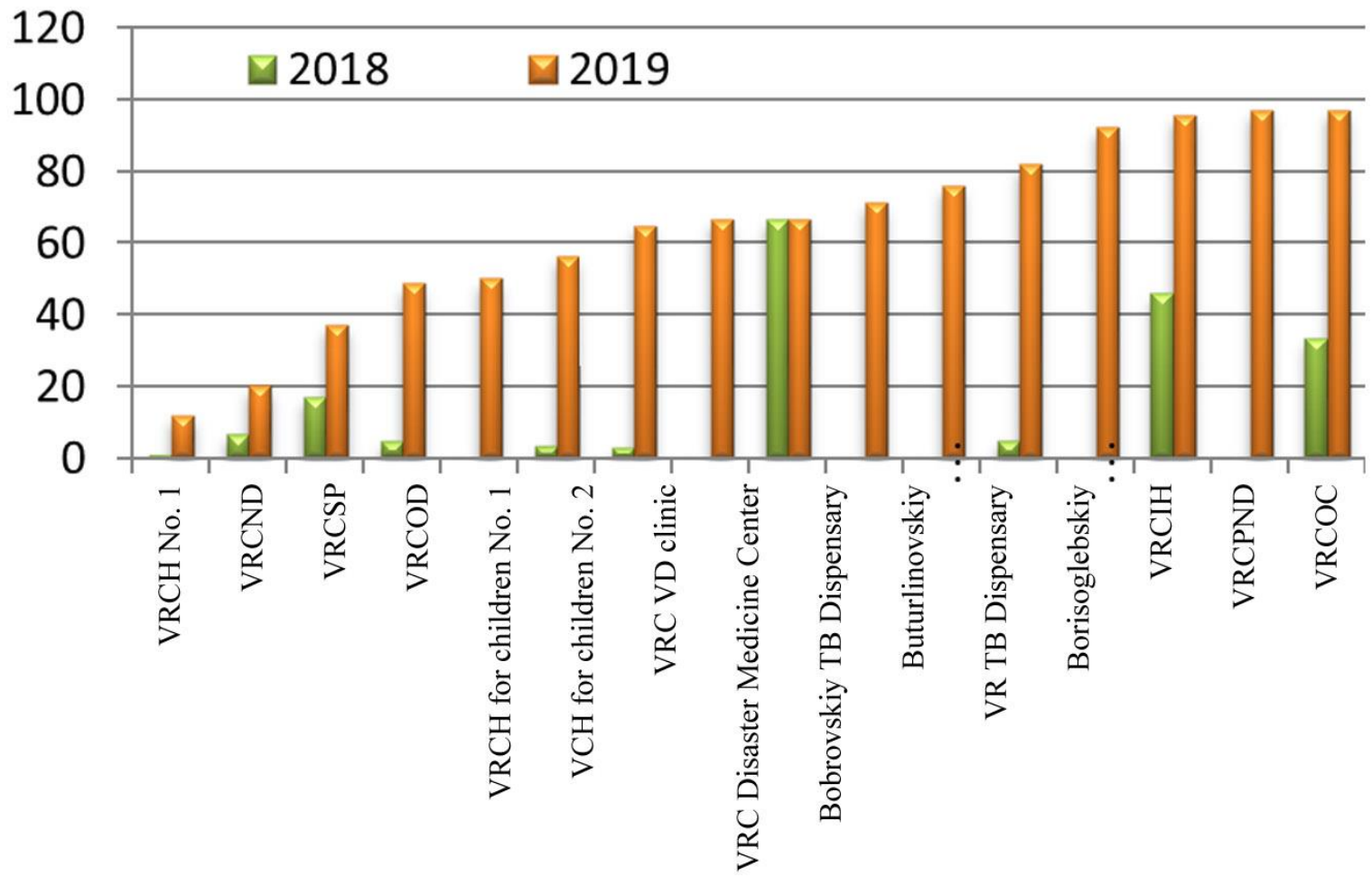

Fig. 1. Connection of automated workplaces in a medical organization to a medical information system 


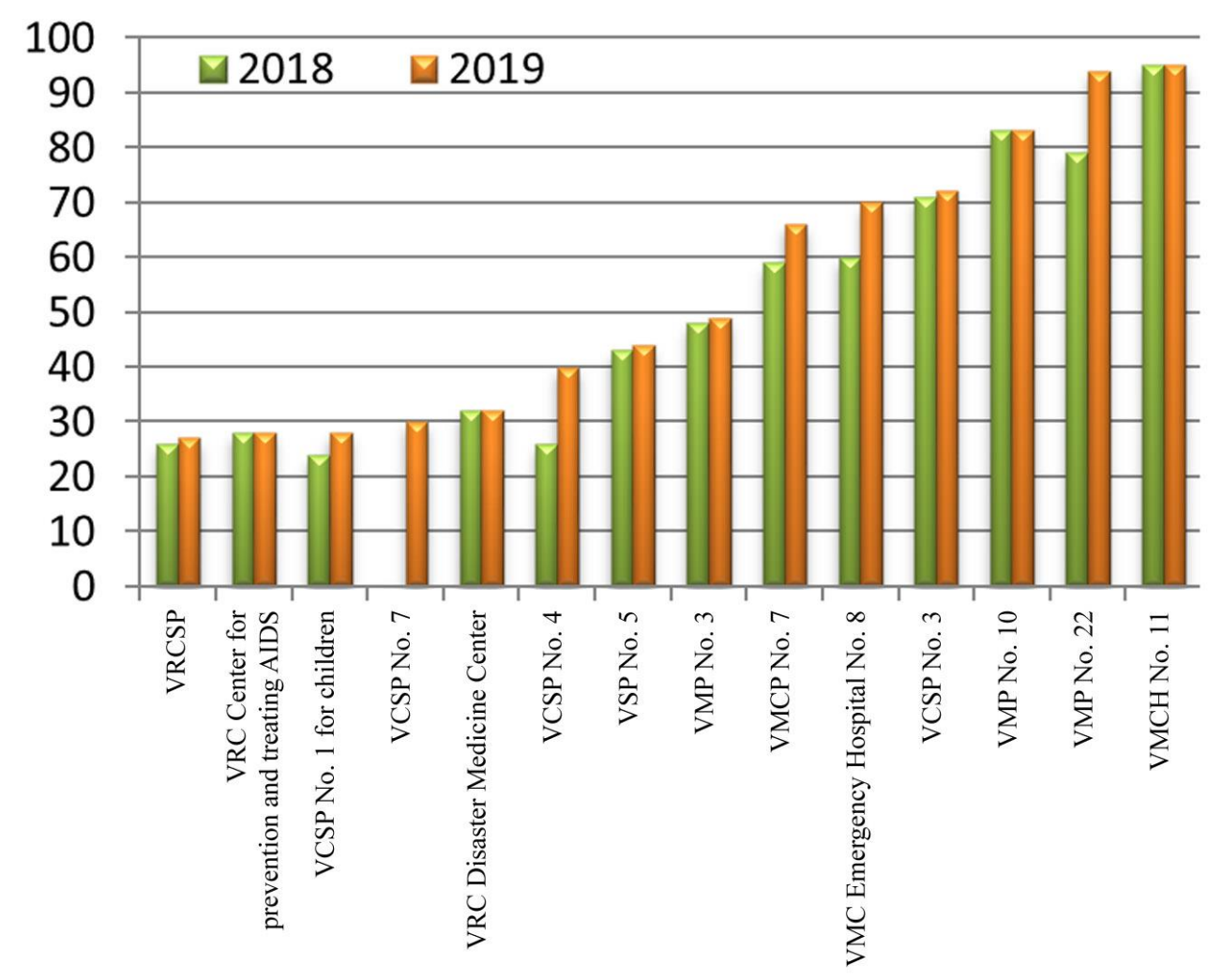

Fig. 2. Percentage of doctors providing medical care in outpatient conditions, the information about the schedule of admission of which is transmitted to the subsystem of the federal electronic registration system of the SSISHC

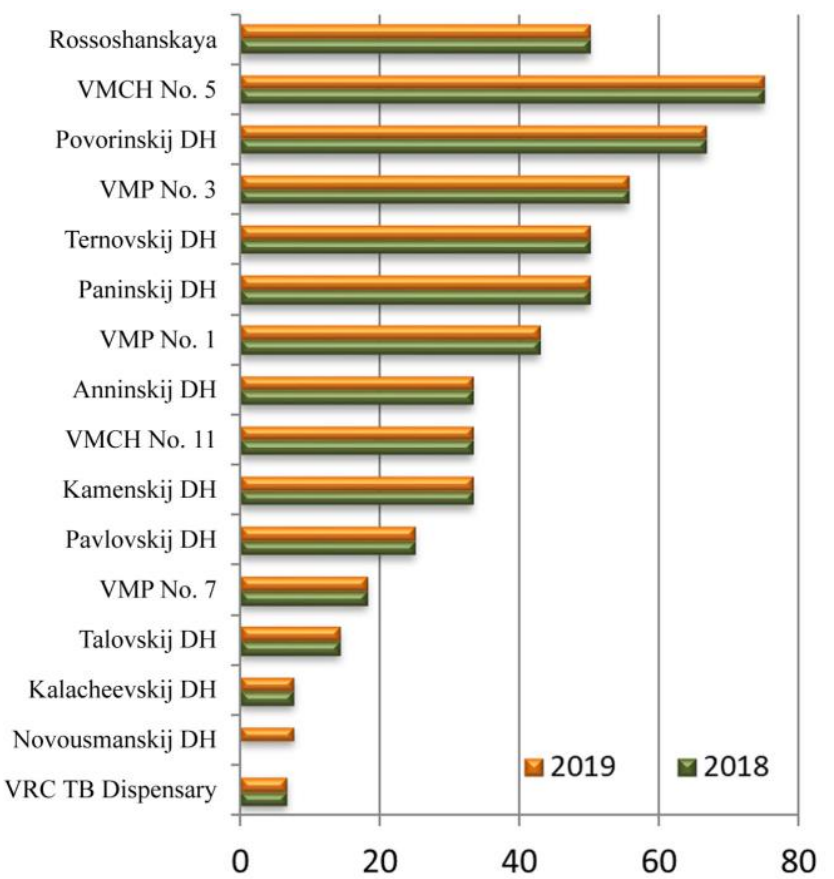

Fig. 3. Medical organizations that organize the processes of providing medical care using telemedical technologies
Proceeding from the purposes of efficient development of the interbudgetary transfer, additional funds have been allocated from the regional budget for the development of the infrastructure of medical organizations providing primary health care. Preparatory measures were taken to master the regional subsidy and to hold competitive procedures for purchasing automated workplaces for medical personnel.

In recent years, many complex problems have been more actively addressed in the region, which has quickly matured under the conditions of intensive development of informatization of health care. For example, the development of telecommunications means of communication has been significantly stepped up and experience in the practical application of telemedicine has emerged.

The work on connecting hospitals and polyclinics to highspeed Internet has already been completed with acceptance tests of 36 points. By the end of the year, it is planned to connect 105 more units of medical organizations. A comprehensive assessment of the effectiveness of measures implemented within the framework of the personal data protection system to ensure the safety of personal data in Personal data information system has been made. District and municipal medical organizations have been trained to work with the modernized and updated Telemedicine system for medical personnel and IT specialists. 


\section{DISCUSSION}

At present the formation of databases for the unified information space of the industry is actively going on, the union of disparate information-computing, statistical, organizational-methodical and other structural and functional divisions into unified information-analytical centers and services of the territory are carried out. Educational and production structures for the training and retraining of medical personnel in the use of computer technology are being actively developed.

The inclusion of information and analytical centers in the nomenclature of health care institutions should be regarded as a serious step in strengthening information support for regional health care management, which makes it possible to raise this type of activity to a new, higher level.

Summarizing the report on the activity of Voronezh Oblast in the sphere of health care, we would like to mention two key problems, which often remain beyond the attention of scientists and practitioners, but are extremely important for improving the efficiency of information technologies development at all hierarchical levels of health care.

The first problem is the lack of integration of management, informatization, and computer technology development processes. This leads to the fact that it is often forgotten that computer systems are an extremely important element, but only one of the tools to improve management techniques. The lack of balance slows down the improvement of management efficiency in the health care sector based on information support for the tasks of forecasting and planning expenditures on medical care, as well as control over compliance with state guarantees in terms of the volume and quality of its provision. Moreover, with the use of automated information systems, the role of a responsible person, a decision-maker and information and analytical support services are changing dramatically, and understanding of which is still slow.

No less important is the lack of formalization of ideas about where we are at the stage of development, in what direction we are moving, what priorities should be chosen and what awaits us in the near and distant future. Although the processes of digitalization of data in health care are already irreversible, their effectiveness may vary significantly from the objective use of the patterns of their development. And it is extremely useful to understand and use different approaches to identifying the stages of computer informatization technologies development.

A lot has been done, but more needs to be done. And we can hope for success if interest, support, and mutual understanding at all levels are further developed and deepened based on succession of generations of specialists. Provided that the main priorities of the Russian Federation information policy concept are realized, one should expect the dynamics of the health care informatization process and profitability of its results. Proceeding from this condition, one can hope for a favorable forecast of the development of medical technologies in the nearest and distant future. In general, this period will be characterized by a paperless intellectual technology of doctor's work, preferential use of databases and knowledge banks, quite a high degree of system integration, saturation of computer facilities about the number of jobs of about 30-40\% by the end of the project period, quite a sharp improvement in the final indicators of health care about $10-15 \%$ in the main indicators (morbidity, temporary disability, disability and mortality in the working-age). It should be noted that the improvement of these indicators through the expansion of medical technologies with the use of information technology will be highly cost-effective and highly efficient.

\section{References}

[1] G.S. Armashova, "Lean production as a factor of competitiveness of a business entity", Proc. of Voronezh State Univer. of Engineer. Technol., vol. 81, no. 2, pp. 336-340, 2019.

[2] A.V. Vladzimirsky, G.S. Lebedev, Telemedicine, Moscow: GEOTARMedia, 2018, $576 \mathrm{p}$

[3] A.V. Gusev, "Creation of regional fragments of the EHISP: current results and analysis of programs for the further development of information systems in the field of healthcare", Doctor and Information Technologies, no. 6, pp. 14-24, 2013.

[4] A.V. Gusev, F.A. Romanov, I.P. Dudanov, A.V. Voronin, Medical Information Systems. Petrozavodsk: Publ. House, PetrSU, 2005, 404 p.

[5] The concept of creating an information system in healthcare for the period up to 2020. Retrieved from: http://www.medwork.ru/content/ kontseptsiya-sozdaniya-informatsionnoi-sistemy-v-zdravookhranenii-naperiod-do-2020-goda (11/04/2015).

[6] G.S. Lebedev, "Review of national health informatization standards identical to international standards", Bull. of new medical technol., vol. XVI, no. 3, pp. 125-129, 2009.

[7] G.S. Lebedev, "Regulatory support of informatization of healthcare and telemedicine", Clinic, no. 1, pp. 62-64, 2014.

[8] Materials for the preparation of the Roadmap for the development of a unified state system in the healthcare sector for 2015-2018, by the constituent entities of the Russian Federation. Retrieved from: http://www.rosminzdrav.ru/informatizacia-zdravoohranenia (11/08/2015).

[9] R.M. Yusupova, R.I. Polonnikova (ed.), Telemedicine. New information technologies on the threshold of the 21st century, St. Petersburg, LLP Publ. House "Anatolia", 2003.

[10] A.V. Danilov, T.B. Katashina, E.A. Isaenkova, E.S. Katashina, "Benchmarking technology for medical organizations of the region as a tool to increase their competitiveness in the Voronezh region", Appl. Inform. aspects of medicine, vol. 21, no 1, pp. 110-113, 2018.

[11] Russian healthcare in the new economic conditions: challenges and prospects. HSE Report on Health System Development. Moscow, 2017, $85 \mathrm{p}$.

[12] Decree of the President of the Russian Federation of 05.05.2018, no 204 "On national goals and strategic objectives of the development of the Russian Federation for the period until 2024".

[13] L.N. Chudinova, N.V. Sirotkina, A.Yu. "Goncharov, An integrated approach to assessing the effectiveness of investment support for sustainable balanced development of the region", Proc. of the SouthWest State Univer., vol. 6, no. 63, pp. 108-116, 2015.

[14] I.E. Esaulenko, T.N. Petrova, A.Yu. Goncharov, V.I. Popov, A.V. Chernov, "Main directions for improving the regional public health protection system", Res. J. of Pharmaceut., Biologi. and Chem. Sci., vol. 9, no. 1, pp. 126-130, 2018 